\title{
Posterior urethral stenosis after prostate cancer treatment: contemporary options for definitive management
}

\author{
Arman A. Kahokehr, Andrew C. Peterson, Aaron C. Lentz \\ Division of Urology, Duke University Medical Center, Durham, NC 27710, USA \\ Contributions: (I) Conception and design: All authors; (II) Administrative support: All authors; (III) Provision of study material or patients: AA \\ Kahokehr, AC Lentz; (IV) Collection and assembly of data: AA Kahokehr; (V) Data analysis and interpretation: All authors; (VI) Manuscript writing: \\ All authors; (VII) Final approval of manuscript: All authors. \\ Correspondence to: Dr. Arman A. Kahokehr, MB, PhD, FRACS. Reconstructive Urology Fellow, Division of Urology, Duke University Medical \\ Center, DUMC 3146, Duke Clinics, 40 Duke Medicine Circle, Room 1113, Durham, NC 27710, USA. Email: arman.kahokehr@duke.edu.
}

\begin{abstract}
Posterior urethral stenosis (PUS) is an uncommon but challenging problem following prostate cancer therapy. A review of the recent literature on the prevalence of PUS and treatment modalities used in the last decade was performed. A summative narrative of current accepted techniques in management of PUS is presented, and supplement with our own experience and algorithms.
\end{abstract}

Keywords: Prostate; cancer; urethra; stenosis; stricture

Submitted Nov 24, 2017. Accepted for publication Mar 01, 2018.

doi: $10.21037 /$ tau.2018.04.04

View this article at: http://dx.doi.org/10.21037/tau.2018.04.04

\section{Introduction}

Posterior urethral stenosis (PUS) is an uncommon but challenging problem faced by urologists. PUS may develop following radical prostatectomy, radiotherapy, and other energy ablation modalities for cancer or transurethral surgery for benign disease of the prostate. Because PUS is uncommon and the patient population is heterogenous, high quality randomized evidence for the management of PUS is needed. Repeated failed treatment may lead to recalcitrant PUS, urinary-pubic symphysis fistula, osteomyelitis, recto-urethral fistula, and other debilitating complicating issues that may need definitive surgical repair, extirpation, and urinary diversion (1). This is not an easy option in some patients with high surgical risk and/or limited life expectancy.

Recent surveys show that urologists have a varied distribution of surgical approaches and algorithms in treating PUS which may be due to differences in understanding of the etiology of this complex situation (2). This has led to a heavy reliance on repeated endoscopic treatments. The aim of this narrative review is to provide an update on contemporary surgical options, supplemented with our own institutional experience.

\section{Terminology}

In this review we have elected to use the term PUS as an umbrella term to refer to ANY pathological narrowing from the bladder neck to the bulbomembranous urethra. PUS is typically seen following radical prostatectomy [at the vesicourethral anastomosis (VUA), pelvic radiotherapy (primary, adjuvant, or salvage) or other energy ablative technologies (high energy focused ultrasound or cryotherapy)]. This is an anatomical and pathological description, a stricture refers to pathological narrowing in the portion of anterior urethra resulting from spongiofibrosis, and we have avoided this term.

\section{Methodology}

PubMed, EMBASE, OVID and Google Scholar searches using the following Boolean operators were carried out from 1990 to August 2017: "posterior urethra" OR "bladder neck" OR "bladder neck" OR "vesicourethral anastomosis", OR "anastomotic stenosis" AND 
Table 1 Prevalence of posterior urethral stenosis (PUS) following prostate cancer therapy based on selected publications in the last decade

\begin{tabular}{|c|c|c|c|}
\hline Study & Intervention & $\mathrm{N}$ & Prevalence of PUS \\
\hline Carlsson 2010 (4) & RALP, RRP & RALP 1,253; RRP 485 & $3 / 1,253(0.2 \%) ; 22 / 485$ (4.5\%) \\
\hline Gillitzer 2010 (5) & RRP,RALP & RRP 866; RALP 2,052 & 33/863 (3.8\%); 113/2,048 (5.5\%) \\
\hline Garg 2009 (6) & RRP & 406 & $3(0.74 \%)$ \\
\hline Elliott 2007 (3) & $\mathrm{EBRT}+\mathrm{BT}$ & 231 & $12(5.2 \%)$ \\
\hline Elliott 2007 (3) & EBRT & 645 & $11(1.7 \%)$ \\
\hline Sullivan 2009 (8) & HDRBT & 474 & $38(8 \%)$ \\
\hline Singhal (9) & LDRBT & 916 & $34(3.7 \%)$ \\
\hline Mohammed 2012 (11) & EBRT alone & 1,039 & $21(2 \%)$ \\
\hline Uchida 2006 (12) & HIFU & 63 & $15(24 \%)$ \\
\hline Ahmed 2009 (13) & HIFU & 172 & $51(30 \%)$ \\
\hline Elliott 2007 (3) & Cryotherapy & 199 & $5(2.5 \%)$ \\
\hline Rodriguez 2014 (14) & Cryotherapy & 108 & $2(1.9 \%)$ \\
\hline Aus 2002 (15) & Cryotherapy & 54 & $9(17 \%)$ \\
\hline
\end{tabular}

RRP, retropubic radical prostatectomy; RALP, robot assisted laparoscopic radical prostatectomy; LDRBT, low dose rate brachytherapy; HDRBT, high dose rate brachytherapy; EBRT, external bean radiotherapy; HIFU, high energy focused ultrasound.

"prostatectomy" OR "prostate" OR "radiotherapy" OR "HIFU" OR "Cryotherapy". We also searched the index of relevant published articles and abstracts from national and international meetings. We included our institutional experience to supplement the narrative.

\section{Prevalence of PUS based on cancer treatment modality}

When comparing the prevalence of PUS following prostate cancer treatment in the last decade, there is variation based on etiology with respect to treatment modality; however, this is commonly under $10 \%$ as demonstrated in Table 1. The prevalence of anastomotic stenosis after $\mathrm{RP}$ ranges from $4.8-8.4 \%(3,16)$ and $0.2-5.5 \%$ following robotic assisted laparoscopic radical prostatectomy (RALP) $(4,5,7)$. Following EBRT alone $2-4 \%$ developed new strictures $(3,10)$. Brachytherapy, especially in combination with EBRT, resulted in higher rate of $5-12 \%(8,10,17)$.
In a recent meta-analysis of 5,849 patients undergoing brachytherapy (BT), the pooled prevalence of strictures after brachytherapy is estimated at 1.9\% (95\% CI: $1.3-$ 2.4\%) (AWAD). There was no difference of prevalence seen when comparing low versus high dose rate BT. In another contemporary study, the incidence of PUS after LDRBT or HDRBT monotherapy was 4\% (11).

Newer energy modalities such as high intensity focused ultrasound (HIFU) are less well studied with regards to long term urethral toxicity. Following HIFU an exceptionally high number of men (24-30\%) have required intervention for "necrotic or stricture" tissue in the prostate with Foley or suprapubic catheterization in the earlier follow up period $(12,13)$. We await further data with regards to the long term urethral toxicity following HIFU as it is unclear if transient sloughing urethral tissue and edema leads to permanent PUS. Following cryotherapy, there is a wide variation in the prevalence of PUS from $1.9-17 \%$ indicating significant heterogeneity in definition used, follow up time, 
Table 2 Characteristics of selected publications on treatment of posterior urethral stenosis (PUS) technique

\begin{tabular}{|c|c|c|c|}
\hline Published technique & $\mathrm{N}$ & Level of evidence, study design, setting & $\mathrm{N}$, data, strengths and limitations \\
\hline $\begin{array}{l}\text { Laser incision and } \\
\text { Triamcinolone bladder neck } \\
\text { injection (20) }\end{array}$ & 24 & $\begin{array}{l}4, \mathrm{RP}, \text { no radiation, previous attempted to } \\
\text { treat in } 79 \%\end{array}$ & $\begin{array}{l}7 \text { required second treatment. } 83 \% \text { had patency at } \\
\text { mean } 24 \mathrm{~m} \text { follow up, incontinence seen in } 17 / 24\end{array}$ \\
\hline $\begin{array}{l}\text { Transperineal } \\
\text { reanastomosis }(21)\end{array}$ & 15 & $\begin{array}{l}4 \text { case series, post prostatectomy BNC } \\
\text { multiple prior [3] treatment failures, } \\
\text { radiotherapy not reported }\end{array}$ & $\begin{array}{l}93 \% \text { success after mean follow up } 20.5 \text { months. } 93 \% \\
\text { incontinent , } 10 \text { AUS with double cuff placed }\end{array}$ \\
\hline $\begin{array}{l}\text { Bulbomembranous } \\
\text { urethroplasty for EBRT (23) }\end{array}$ & 35 & $\begin{array}{l}\text { 4, case series, all post radiotherapy-no RP } \\
\text { cases }\end{array}$ & $\begin{array}{l}\text { At } 50 \text { months follow up } 30(86 \%) \text { had cystoscopic } \\
\text { patency }\end{array}$ \\
\hline $\begin{array}{l}\text { Bulbomembranous stricture } \\
\text { perineal urethroplasty (24) }\end{array}$ & 72 & $\begin{array}{l}4, \text { case series, all post radiotherapy-no RP } \\
\text { cases }\end{array}$ & $\begin{array}{l}\text { Multi-institutional, } 70 \% \text { success with excision and } \\
\text { primary anastomosis }\end{array}$ \\
\hline $\begin{array}{l}\text { Retropubic open } \\
\text { reconstruction of bladder } \\
\text { neck (25) }\end{array}$ & 20 & $\begin{array}{l}\text { 4, case series, post RP. Radiotherapy } \\
\text { status not reported }\end{array}$ & $\begin{array}{l}8(40 \%) \text { recurrence rate, but } 7 / 8 \text { treated with single } \\
\text { endoscopic treatment, overall success being } 19(95 \%) \\
\text { at follow up of median } 63 \text { months }\end{array}$ \\
\hline $\begin{array}{l}\text { Retropubic open, perineal, } \\
\text { or combined reconstruction } \\
\text { (26) }\end{array}$ & 12 & $\begin{array}{l}4 \text {, case series, post prostatectomy, } n=3 \\
\text { following radiotherapy }\end{array}$ & $\begin{array}{l}8 / 12 \text { cases had pubectomy. } 8 / 12 \text { cases needed } \\
\text { secondary procedure (AUS, repeat reconstruction). } \\
\text { Overall urethral voiding in } 11 / 12\end{array}$ \\
\hline
\end{tabular}

RP, radical prostatectomy; BNC, bladder neck contracture; HDRBT, high dose rate brachytherapy; EBRT, external bean radiotherapy; AUS, artificial urinary sphincter.

or technique of reporting $(3,14,15)$. Again longer follow up data is needed, however it is possible that the rate of PUS following these modalities may reduce with experience gained by the practitioners of these therapies. Table 2 outlines the characteristics of selected publications we will discuss on treatment of PUS.

\section{Initial evaluation}

In our experience, patient presentation to clinic can be simply divided in those who are voiding per urethral, and those who have a drainage tube already placed by the referring physician (suprapubic or urethral). Patient evaluation by history and physical examination, validated questionnaires (IPSS), and voiding diary are routine. Laboratory and procedural investigations include urine culture, metabolic profile of upper tracts with a $\mathrm{Cr}$, uroflowmetry, post void residual measures. Awake urethrocystoscopy allows evaluation of the anterior urethra, tissue integrity, location and length of the PUS (if passable), and the presence of other complicating factors such as foreign bodies (surgical clips) (28), stones, or tumors. In some patients with incontinence, pad weight measurement and urodynamics should be considered. This is especially important in the cancer survivor who may also be afflicted with urinary incontinence. We typically reserve urodynamics for patients who have lower urinary tract symptoms which may be attributable to bladder dysfunction 


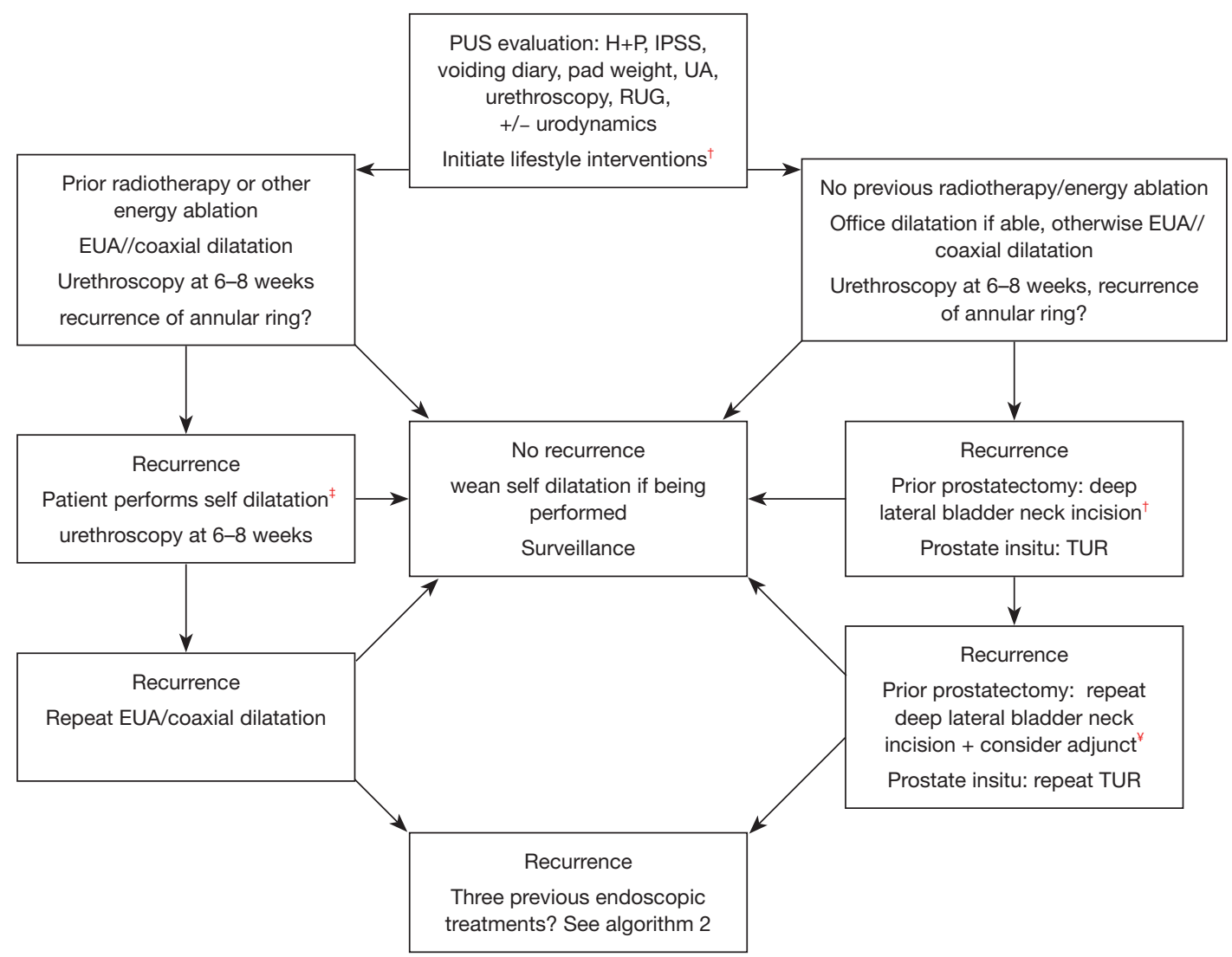

Figure 1 Duke University algorithm for initially treating posterior urethral stenosis (PUS) in patients voiding per-urethra. $\dagger$, lifestyle interventions: smoking cessation, optimize diabetes and other chronic illness. ‡, self-dilatation protocol: Week 1—perform CISC once a day; Week 2 and 3-perform CISC every second day; Week 3 to 5-perform CISC every 3rd day; Week 6 to 10-perform CISC twice a week; Week 10 to 12 -perform CISC once a week then stop. $¥$, adjuncts to endoscopic therapy: Balloon dilatation—patient performed, Mitmycin C or steroid injection. EUA, evaluation under anesthesia; RUG, retrograde urethrogram; UA, urinalysis; TUR, transurethral resection; CISC, clean intermittent self catheterization.

(e.g., underactive detrusor), those with bothersome urinary incontinence, as well as those whom no longer desire urethral voiding. In this population, urodynamics gives us information when considering bladder sparing versus non sparing urinary diversion. Cystometric capacity, compliance, signs of reflux as well as detrusor overactivity is assessed when making important decisions towards urinary diversion. We may selectively use retrograde urethrogram (RUG) in those with suspected bulbar-membranous stenosis or in those with complete obliteration (this may be combined with an anterograde cystogram to estimate the length and location of the obliterated segment).

Based on our experience, we have developed two algorithms (Figures 1,2) which are used for patients who are and are not tube dependent. Patients are further divided into those with/without a prostate in situ.
Figure 3 outlines the approach to those who or no longer wish to void urethrally. We recommend eliminating smoking, and optimizing chronic metabolic conditions, such as poor nutrition/diabetes prior to surgery.

\section{Initial endoscopic treatment}

For short, non-obliterative strictures, initial endoscopic evaluation under anesthesia (EUA) and endoscopic treatment is usually performed as this is relatively simple, usually safe (although one has to be vigilant about risks of fistulization after aggressive endoscopic or repeated treatment) (29). In the prior untreated, non-radiotherapy cases with soft appearing short PUS (often at the VUA following radical prostatectomy) the least invasive treatment such as office cystoscopy and dilatation using 

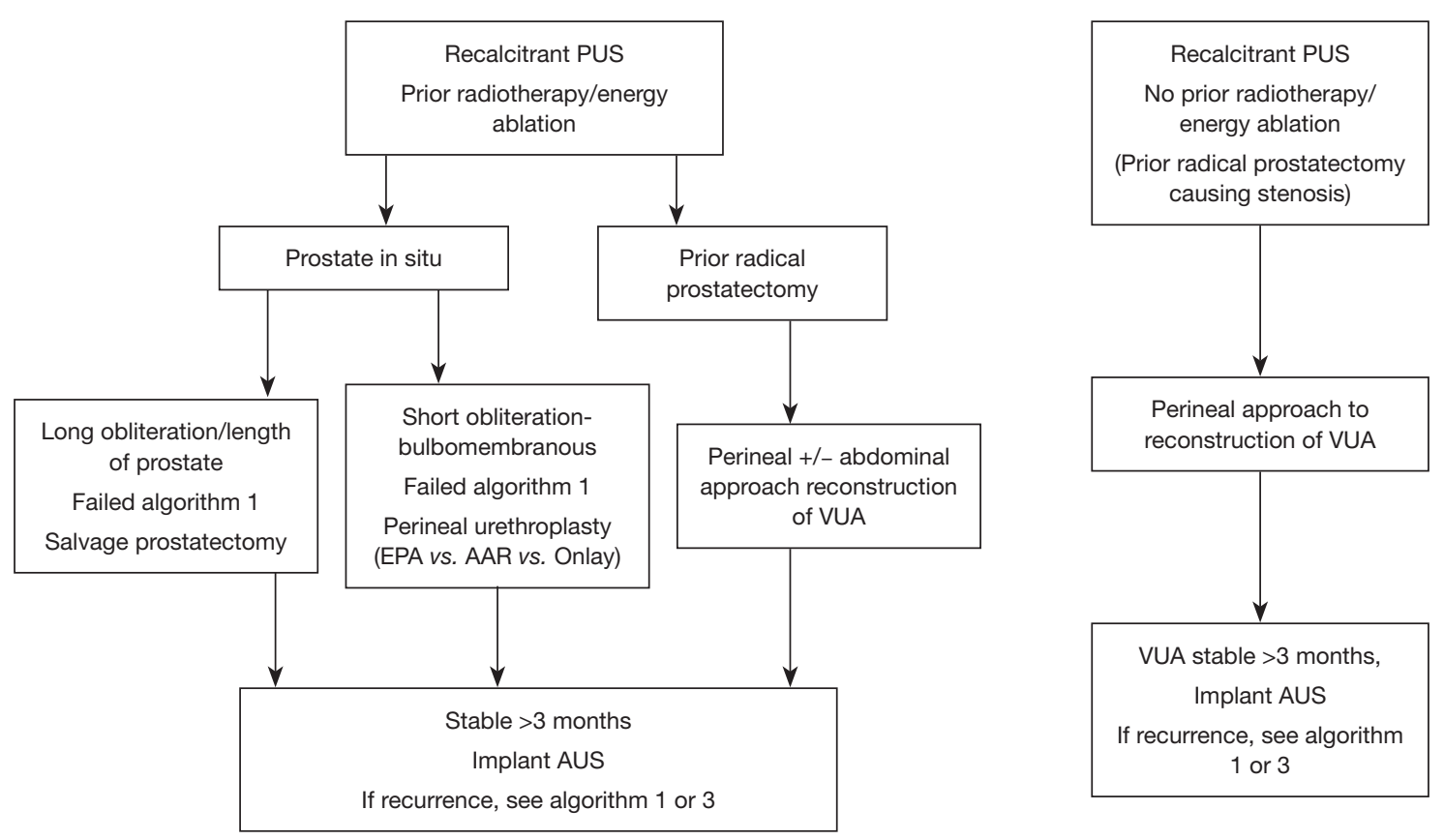

Figure 2 Duke University algorithm for treating posterior urethral stenosis (PUS) that are recalcitrant or completely obliterated with previously failed endoscopic treatments when urethral voiding is still desired. EPA, excision and primary anastomosis; AAR, augmented anastomotic repair; VUA, vesicourethral anastomosis; AUS, artificial urinary sphincter.

serial dilators or balloon over a guide wire may replace an EUA. In cases with short, non-obliterated stenosis at the bladder neck, sometimes no further intervention is necessary after the initial endoscopic treatment. This is rare in our experience as those cases are "self-selected" by the initial therapy performed in the community and we often face recalcitrant PUS. The uncontrolled nature of studies reported in the literature leads to wide variations in quoted recurrence rate. Stricture free rate in all strictures range from $10-90 \%$ and generally decrease with the length of follow up (30). Dilation and endoscopic incision of short bulbomembranous urethral stricture caused by radiation is often reported with high success in the radiation oncology literature $(8,31)$. There is a paucity of data on long-term follow-up and recurrence following these endoscopic options. The same authors later publishing that nearly one third required repeat dilatation, again with lack of follow up data (32). Hence we are cautious when interpreting these data regarding single dilatation success rates in the irradiated setting.

At the bladder neck, balloon dilatation immediately followed by deep lateral electrocautery transurethral incisions to peri-vesicle fat has is successful in $72 \%$ after one procedure, $14 \%$ needed a second procedure, making overall success very acceptable (18). Those with prior multiple endoscopic procedures are at higher risk of failure. It is important to point out that incision at the bladder neck following RP is different when compared to a contracture at the bladder neck following transurethral resection of prostate (TURP). In the post TURP setting incontinence is less likely, as area of incision is proximal to the external sphincter. In the post prostatectomy setting, care must be taken with any transurethral approach as the risk of pronounced incontinence is much higher, and sometimes unavoidable. We always counsel patients about this impending incontinence, the priority is given to patency, and the possible need for a second stage treatment with artificial urinary sphincter is always discussed.

In cases with previous dilatation failure, longer stenosis, or history of energy ablation or radiotherapy, the transurethral incision using hot electrocautery Collin's knife has been utilized. Endoscopic incisions using the cold knife, laser, and loop resection are also common techniques. There is a lack of a standardized algorithm with which modality to treat (2). The importance of endoscopic management is to ensure the incisions are placed laterally to avoid rectal injury, extravasation to pubic symphysis, and minimize further injury to the external sphincter. 


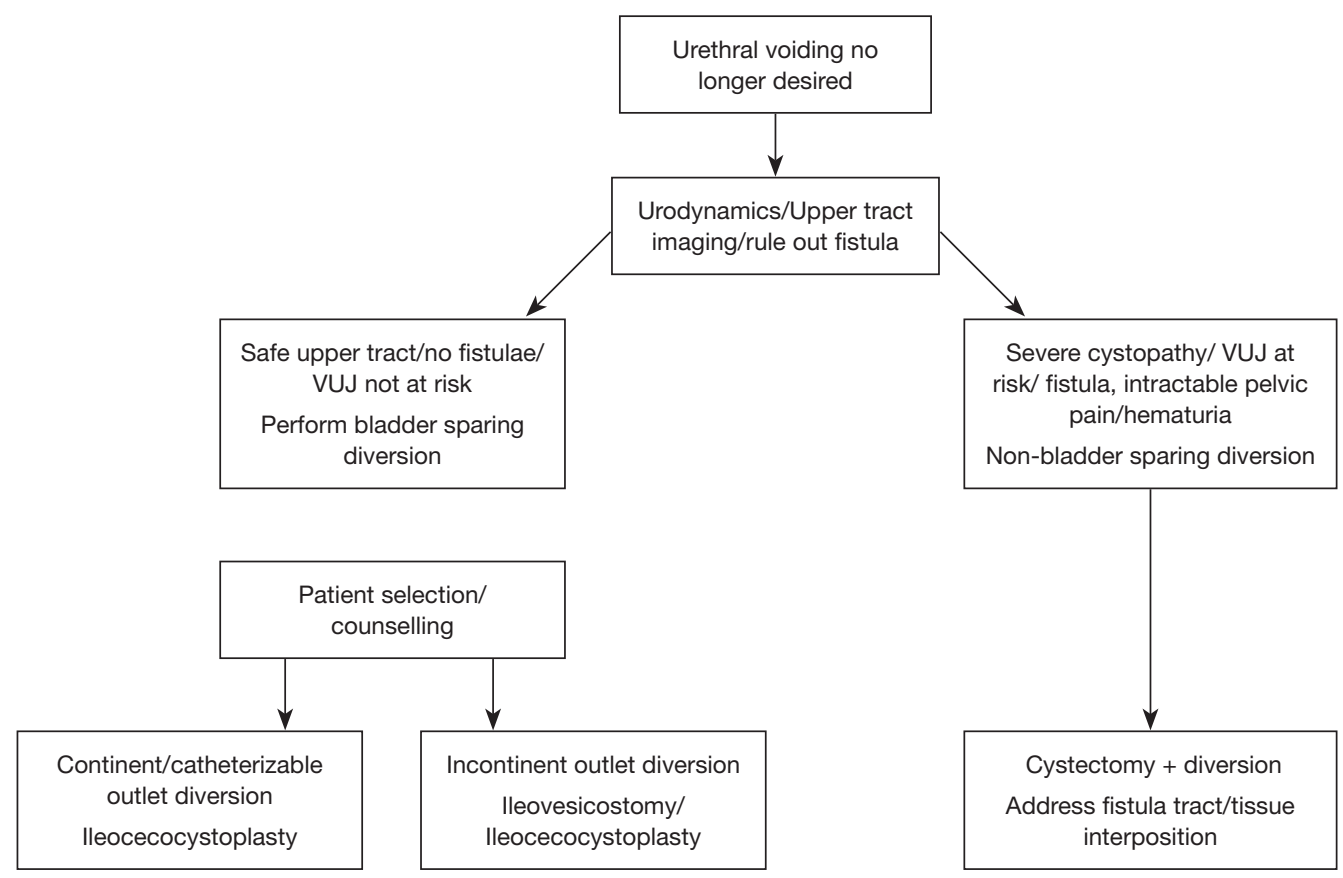

Figure 3 Duke University algorithm for treating posterior urethral stenosis (PUS) that are recalcitrant or completely obliterated with previously failed endoscopic treatments and urethral voiding is no longer desired. VUJ, vesico-urethral junction.

Based on global experience, endoscopic treatment is likely to have better long term results in non-radiated patients, however recurrence is still high. Recurrence was seen in $49 \%$ of patients with post radiation bulbomembranous strictures after internal dilatation or urethrotomy (8). Incontinence in this population is often high and severe following these maneuvers. The risk of urinary fistula to anterior and posterior organs increases with repeat endoscopic manipulation $(29,33,34)$. Extra care is needed to avoid extravasation following dilatation in these settings and avoid repeated traumatic incisions. Hence based on our experience with radiotherapy complications $(1,35)$, we use the presence of radiotherapy/energy ablation as an important factor when determining a step wise approach to PUS (Figures 1-3). A recent systematic review by the authors (manuscript in preparation) shows that $75 \%$ of patients who developed a urinary-pubic symphysis fistula and chronic osteomyelitis had a history of prior endoscopic manipulation of the posterior urethra. The data is very limited due to the retrospective nature of all studies, allowing many aspects of bias such as recall. We believe this figure in reality is probably closer to $90 \%$ and are limited by the data. The denominator of those with complex fistulae is not known as importantly there has never been a prospective study of fistulae following TUR for PUS/BNC.
Hence the true prevalence of these conditions cannot be assessed based on the current state of the literature.

\section{Adjuncts to endoscopic treatment}

There has been an interest in adjuncts in order to improve the long term patency rate of endoscopic treatment. Involving the patient or attempting to modify the stricture pathophysiology (by injecting anti-inflammatory or cytotoxic medicine) are new strategies used to improve recurrence rate following endoscopic treatment.

\section{Self-dilatation and calibration}

In selected patients whom are compliant and motivated, one option is to perform intermittent urethral balloon dilatation and regular office review. We have found that the $18 \mathrm{~cm}$ Urethral Balloons dilation system (Cook Medical Inc., Bloomington, IN) useful as this is easiest for patients to traverse the PUS and inflate effectively. Patients are taught to hub the balloon at the meatus in order to ensure effective crossing of the PUS. This is inflated for 10 minutes twice per day followed by cystoscopy at 6 weeks. If at that point annularity of the VUA is seen, another transurethral incision is attempted. If not, the inflation protocol is weaned to once per day for 3 months and gradually stopped. 
It can occasionally take up to a year to achieve complete control and freedom from balloon dilatation. We have a select number of patients that insist on continuous selfdilatation because of the relief they have experienced and fear of re-stenosis. In those with prostate $i n$-situ, endoscopic management with judicious resection of the urethral stenosis or "channel TURP" remains is an option if the high risk of severe incontinence is accepted.

\section{Bladder neck pharmacotherapy injection}

In an attempt to control PUS especially at the bladder neck, there has been an interest to control (or at least slow) chronic inflammation and repeat scar formation. Corticosteroids have anti-inflammatory properties and are widely used in medicine. Triamcinolone injected into the incision sites after deep lateral laser incision of VUA with relatively good results has been published. Nineteen of the 24 patients in the study had at least one previous attempt of surgical treatment. At a mean follow up of 24 months, $19(83 \%)$ patients had widely patent bladder neck, 17 had incontinence (20).

Mitomycin C (MMC) has previously been successfully used to prevent tracheal scar tissue formation in the field of pediatric otolaryngology. MMC interferes with the ability of fibroblasts to produce scar without causing changes in epithelialization. In the original study of 18 patients, (17 post RP, 2 had received adjuvant radiotherapy with at least one prior attempt of treatment) patients received tri or quadrant cold knife bladder neck incision to peri-vesicle fat followed by 0.3 to $0.4 \mathrm{mg} / \mathrm{mL}$ MMC injection at each incision site (19). At median follow up of 12 months, 13 (72\%) patients had a stable bladder neck and only three patients needed a second procedure. One patient required four procedures to reach stable control of the bladder neck. Transient perineal discomfort was seen and resolved at 3 months in two men. In a large case series with similar surgical methodology to that described above, MMC was used to treat VUA stenosis including 14 (25\%) with a prior history of pelvic radiotherapy. Thirty two of 55 (58\%) had durable resolution after one incision and MMC treatment after a median follow up of 9.2 months (36). A second incision and injection was performed in 15 patients, improving the cumulative success rate to $41 / 55$ (75\%). In another case series of 29 patients (post RP, $28 \%$ who had also received EBRT) MMC injection in the VUAS followed by dilatation was successful in $23(79 \%)$ of patients within the first 12 months. However 3 required repeat injection (37).

The long term effects of injection of cytotoxic and steroids into the bladder neck are not known, especially in those with a history of previous pelvic radiotherapy. We typically reserve the use of injectable therapy using steroid or MMC in non-radiated patients. Systemic and local side effect of MMC can be devastating, including fistulation, in those cases reported (36). Long term durability and surveillance data following these adjuncts are awaited and concern regarding long term safety remains.

\section{Urethra stenting (endourethral prostheses)}

The UroLume (American Medical Systems, Minnesota, USA) which was first used in 1988 (38) and is no longer being marketed. Complications associated with this stent were erosion, tissue overgrowth, calculus and infection. Placement of this stent also resulted in high (as expected) incontinence rate. In our institutional experience, a 12-year review of 45 men with mean follow up of 56 months revealed that the majority required artificial urinary sphincter (AUS) placement for post UroLume incontinence, achieving an overall continence rate of 78\% (39). In 16 (36\%) patients who developed ingrowth 2-3 endoscopic procedures on average was needed. In $8(20 \%)$ patients AUS erosions occurred that was not otherwise associated with tissue ingrowth. Other known complications associated with this device are migration, encrustation, infection, hematuria. The Allium (Allium Medical, Israel) and Spanner ${ }^{\mathrm{TM}}$ (SRS Medical, MA, USA) prostate stents are newer devices utilized for patients who cannot undergo more invasive procedures. The outcomes of these are not known for those with PUS and unlikely to be of major advantage over previous experience in long term urethral stenting.

\section{Novel endoscopic treatments}

Recently described is an anterograde endourethroplasty technique utilizing free inner arm skin graft in 11 patients. The graft bed was prepared by transurethral resection of the VAUS. Three days later, access to the bed was obtained via suprapubic amplatz sheath and the tubularized skin graft was introduced on an endobronchial tube balloon, placed anterogradely under endoscopic vision and fixed by two sutures placed percutaneously from the perineum. A transurethral catheter was removed after 3 weeks. Overall, 6 (55\%) patients had successful urethral patency at 2 months, Graft necrosis occurred in 2 patients, and re-stricture was seen in 3 patients (40). We await further reports and longer follow up on this technique before recommendation can 
be made given the perceived challenges in performing this procedure.

\section{Surgical reconstruction of the bladder neck- perineal approach}

In cases of failed or failing endoscopic strategies mentioned previously, more aggressive surgical treatment may be needed for long term stability of the bladder neck. Reconstruction of the PUS can be achieved by several described methods.

\section{Perineal approach for non-obliterated anastomosis or "bladder neck" contracture}

The majority of men with VUA stenosis and failed endoscopic control can undergo revision of the anastomosis. Pure perineal approach is arguably best in those without prior radiotherapy and good hip flexion, shorter stenosis and good tissue healing (41). A standard midline perineal approach to the urethra is performed and identification of the distal aspect of the stricture using on table cystoscopy. The anterior urethral mobilization from the corporal bodies and intracrural plane developed. The bulbar urethra is mobilized to the site of stenosis identified, and transected. Stricturectomy is performed to healthy bladder neck from the lumen to the periphery until good tissue is observed, a step which requires excellent exposure and best performed by experts. Care to avoid the rectum and trigonal structures is necessary and access may need to be aided by crural separation, dorsal venous complex ligation, and inferior wedge pubectomy. Once adequate mobility allows parachuted anastomosis, dorsal spatulation of the anterior urethra is performed to fashion a tension free, water tight, anastomosis over a urethral catheter. Future placement of the AUS can be aided by placement of a non-absorbable suture or penrose drain on an appropriately identified site of urethra as a future landmark (42). In expert hands, with a mean follow up of 20.5 months (range, 6-37 months) success has been seen in 14 of 15 patients by utilizing this approach (21). In another larger case series of 42 patients after RP (10 with prior radiotherapy who had bladder capacity $>200 \mathrm{~mL}$ ) the transperineal approach was approach was utilized (22). All required crural plane opening and wedge pubectomy and AUS was utilized as a secondary procedure in 3-6 months. Seven from the 10 patients whom had RP and salvage radiotherapy patients had successful outcome. Two developed incomplete healing and urosymphyseal fistula, one developed restenosis managed by SPC tube. These data demonstrate that in expert hands, selected patients even with radiotherapy may have successful transperineal reconstruction of the PUS.

\section{Abdominal-perineal approach to VUA anastomosis or "bladder neck" contracture}

Following prostatectomy, the bladder neck and bladder mobility may be compromised, and reconstruction of the anastomosis challenging via pure perineal approach. In those deemed to have a difficult or challenging perineal reconstruction, long stenosis, and when the external sphincter is no longer functional the combined abdominal approach to re-anastomose the bladder to urethra may be performed based on surgeon experience and comfort $(41,43)$. At our institution we may perform a pubic bone wedge resection to allow adequate access for reconstruction of the VUA. Graft and flaps may need to be utilized once the bladder neck is exposed abdominally (44). A staged procedure for AUS implantation is performed once the VUA has been stabilized.

\section{Perineal approach to bulbomembranous stenosis due to radiotherapy}

In bulbomembranous stenosis due to radiotherapy, posterior urethroplasty is an option in expert hands. This is becoming more accepted with growing case experiences from academic centers. In a recent series of 35 patients, the mean stricture length was $3.5 \mathrm{~cm}$ and primary anastomosis was performed in $(66 \%)$, buccal mucosa graft in (20\%) and penile island flap in $14 \%$ (23). At 50-month follow up 30 (86\%) had cystoscopic patency. Similarly in another multi-institutional series of 72 men, after a mean time of 6.4 years, $92 \%$ underwent excision and primary anastomosis with successful results in $70 \%$ of patients (24). In cases of severe radio-necrosis of the prostatic urethra resection using a rongeur to ensure complete scar removal to healthy tissue is also performed to facilitate posterior urethroplasty (45). Buccal mucosa grafting also has been reported in radiation induced strictures with over $70 \%$ success at median follow up of 26 months (46). After urethroplasty in the setting of radiotherapy, de novo incontinence occurred in nearly $10-20 \%$ of men with a second stage AUS placed as a secondary procedure.

\section{Surgical reconstruction of the bladder neck- pure abdominal approach}

This approach must be carefully tailored to the patient and 
best performed by experience reconstructive surgeons. The patient is often post energy ablative prostate treatment, the extent of PUS is severe and tissue healing abilities doubtful. Additional comorbidities, poor nutrition, chronic infection and smoking require careful attention. A suprapubic catheter allows time for urethral rest and surgical planning. A mature SPC tract allows easy anterograde access during repair. Full work up is needed to ensure the bladder capacity is adequate and severe cystopathy or other significant pathology such as fistula, does not go unrecognized. Prostatectomy may be needed if not previously carried out. The surgical risks associated are higher in this setting.

Primary re-anastomosis via midline incision after prostatectomy in selected men has good results. After midline retropubic access is secured, the previous anastomosis is taken down and all scar tissue is excised, ureters are stented and distal urethra trimmed to healthy mucosa, bladder neck prepared by tabularization if gaping open, and 6-8 suture VUA fashioned over an $18 \mathrm{~F}$ urethral catheter.

In a report of 20 men who had failed 3.7 prior procedures on average, $12(60 \%)$ patient were recurrence free at a median of 63 months, and 7 required single endoscopic treatment resulting in overall success of 19/20. The remaining patient underwent diversion. There were no AUS erosions in the 9 patients whom underwent placement at median follow up of 79 months (25). In another study, amongst 12 men who had undergone RP, abdominal repair was performed in seven with a median follow up of 46 months (range, 14-120 months), $92 \%$ patency was achieved (26). Retropubic re-anastomosis utilizing fasciocutaneous flaps, free graft urethroplasty with rectus muscle flap or anterior bladder tube with omental pedicle flap have been described and these techniques depend on expertise and surgical team experience, prior interventions, and degree of scar tissue encountered (44).

\section{T-plasty bladder advancement}

This open surgical technique has been recently described, and is a modification of the YV-plasty which was described decades ago. It is important to note that bladder neck advancement flaps are typically reserved for PUS resulting from complications relating to treatment of benign disease, typically at the bladder neck flowing a TURP or similar BPE treatment. In this technique two wide bladder neck flaps are created and sutured in a v-shape to widen the bladder neck through a retropubic, transvesical approach. At a mean follow up of 26 months, there was no recurrence seen amongst ten patients. Patient satisfaction was reportedly high and no de novo stress urinary incontinence occurred (47). It is conceivable that this approach may be utilized in prostate cancer survivors (without prior radiotherapy) although reports of bladder neck advancement techniques in this setting are currently lacking.

\section{Robot assisted laparoscopic surgery for PUS}

The literature in the post cancer treatment setting is scant but emerging, with the majority of case reports carried out in patients following treatment of benign prostatic disease. A case series of 12 consecutive men treated with robotassisted Y-V plasty. All but one patient had undergone prostate treatment for benign disease with one patient having had HIFU. All patients had multiple unsuccessful endoscopic procedures previously and were treated. At a median follow up of 23 months, two patients developed symptomatic refractory BNC (27).

Laparoscopic and robotic techniques have also been described in adult patients undergoing cutaneous vesicostomy formation, and augmentation enteroplasty with catheterizable channels, showing minimally access surgery is feasible in the construction of continent urinary diversion in the adult population $(48,49)$. A recently described hybrid technique for catheterizable ileocecal enteroplasty utilizes a Pfannenstiel hand port for mobilization of the right colon laparoscopically, the ensuing bowel anastomosis and cystoplasty are all performed in an open fashion via the hand port, and the umbilical camera port is utilized to mature the continent catheterizable ileal channel (50). Bladder preserving diversion with robot assisted catheterizable augmentation using an ileocecal segment has also been performed in two patients with reduced bladder capacity and recalcitrant BNC following robot assisted laparoscopic radical prostatectomy (RALP). At 16 and 89 months follow up, patients had stable upper tracts (51).

These recent reports are encouraging, minimally invasive approaches may one day become a realistic option as experience with PUS in cancer survivors (with or without pelvic radiotherapy and previous abdominal surgery) grows. One of the challenges facing minimally invasive surgery is technical aspects of interposition of healthy tissue and these technical challenges of salvage operations will impede widespread use outside of highly specialized units.

\section{Concomitant PUS and incontinence}

Incontinence is the major issue following procedures to 
correct PUS. In fact, we frequently tell men that in order to achieve a stable bladder outlet, we may need to incise aggressively and "abandon" any remaining function of the native sphincter (aware of the fact that the external sphincter is likely to have been previously destroyed). The AUS has excellent safety and satisfaction profile in selected men and can be used as part of a "two step" approach once the PUS has been stabilized. The duration of time between procedures is not agreed upon, with one study advocating for a 6-8-week period (52) which in our experience is too short and we would advocate 3-6-month waiting period prior to incontinence surgery.

The male slings and AUS in selected men may be considered for the management of concomitant incontinence (53) although the AUS is superior in post radiotherapy setting (54). We have previously published work from our institution showing that synchronous endoscopic incision of the VUAS and the AUS placement can be performed safely (55). Simultaneous Implantation of the AUS has also been reported in those undergoing abdominoperineal repair (43). However, despite these reports, it is now our preference to defer simultaneous AUS insertion due to the risk of recurrent PUS and subsequent need for intraurethral assessment which may place the AUS cuff under jeopardy. Hence to ensure long term stability, we prefer to place an AUS after a period of at least 3-6 months after definitive control of the PUS.

\section{Non-reconstructable "devastated" bladder outlet with or without associated pathology}

Typically, but not always, the patient has a history of pelvic radiotherapy or other energy ablative therapies, with multiple previous attempts to cure. Depending on the status of the bladder and ureters, options are based on patient factors, disease limitation, concomitant pelvic pain, fistula, or pelvic sepsis. The last resort treatment option is creation of diversion with or without cystectomy. The decision faced by the patient and surgeon is the feasibility of bladder preservation. A realistic discussion with the patient is a must.

If urodynamic assessment (which can be made unreliable in those with chronic SPC in situ), shows a bladder capacity of $>200 \mathrm{~mL}$, a safe bladder compliance, and there is no severe pathology such as radiation cystitis, it is reasonable to preserve the bladder. A non-continent or continent diversion of the lower tract outlet in the form of an ileovesicostomy, or appendicovesicostomy has the advantage of not needing to mobilize the ureters (56). In those with poor bladder capacity, an ileocecocystoplasty is an excellent option to increase capacity and provide a means of continent diversion. This approach can be done laparoscopically to reduce morbidity. Permanent perineal urethral ligation in males can be performed in cases where the bladder outlet is devastated and bladder preserving cutaneous diversion has resulted in ongoing urethral incontinence $(57,58)$.

Salvage prostatectomy bladder neck closure may need to be performed if the prostate is still in the pelvis (59). In those with significant necrosis and fistula, cystectomy and diversion is definitive and needs a multi-disciplinary approach. Neobladder formation with urethral pull through and subsequent AUS implantation has been reported as an alternative to cutaneous diversion following cystectomy for recalcitrant PUS (60). In a report of 30 patients undergoing urinary diversion following prostate cancer treatment (average of 4.6 years), $20 \%$ had undergone external beam radiotherapy, $37 \%$ underwent brachytherapy, and $43 \%$ underwent combination therapy (61). The indications for urinary diversion including urinary fistula (37\%), devastated bladder outlet $(27 \%)$, and a combination of end-stage bladder and devastated outlet (17\%) end-stage bladder (20\%). It is important to point out that $8(27 \%)$ patients required bowel diversion due to intractable gastrointestinal symptoms, highlighting the complexity in these cases.

\section{The future in understanding PUS}

Understanding the etiology of PUS may give us direction towards preventative measures. Recently the scar tissue RNA of the bladder neck contracture after RP has been compared with healthy human tissue. Alternations in the expression of molecules at this level were found. Although at its infancy, this insight may lead to further understanding of the pathogenesis of $\mathrm{BNC}$, and will hopefully lead to novel treatment strategies (62). Other areas of research include regenerative technologies and the utilization of meshed tissue grafting from autologous cells. A recent report of twenty patients whom underwent two endoscopic injections of placental amniotic allograft following bladder neck incision was safe and $80 \%$ were recurrence free at 8 months median follow up (63). Further research will tell if these novel techniques will make a difference to patient care.

\section{Summary}

PUS is an umbrella term utilized to describe all pathological 
stenosis of the posterior urethra or bladder neck. This is a challenging condition to manage especially in the setting of prior radiotherapy or energy ablation. Treatment must be tailored to the patient and expectations discussed, as the risk of incontinence after treatment is severely increased. New adjuncts to endoscopic treatment such as injectable therapies may improve recurrence rate. Self-managed techniques may avoid invasive surgery and stabilize the PUS in selected patients. Definitive revision and repair via the perineum or abdominal approach has good, although not perfect outcomes in expert centers. Minimally invasive approaches are increasingly being performed for definitive repair. Patients often need secondary procedure to achieve continence after definitive repair. For some patients the only long term option is to perform urinary diversion.

\section{Acknowledgements}

None.

\section{Footnote}

Conflicts of Interest: The authors have no conflicts of interest to declare.

\section{References}

1. Lavien G, Chery G, Zaid UB, et al. Pubic bone resection provides objective pain control in the prostate cancer survivor with pubic bone osteomyelitis with an associated urinary tract to pubic symphysis fistula. Urology 2017;100:234-9.

2. Pfalzgraf D, Siegel FP, Kriegmair MC, et al. Bladder Neck Contracture After Radical Prostatectomy: What Is the Reality of Care? J Endourol 2017;31:50-6.

3. Elliott SP, Meng MV, Elkin EP, et al. Incidence of urethral stricture after primary treatment for prostate cancer: data From CaPSURE. J Urol 2007;178:529-34; discussion 34.

4. Carlsson S, Nilsson AE, Schumacher MC, et al. Surgeryrelated complications in 1253 robot-assisted and 485 open retropubic radical prostatectomies at the Karolinska University Hospital, Sweden. Urology 2010;75:1092-7.

5. Gillitzer R, Thomas C, Wiesner C, et al. Single center comparison of anastomotic strictures after radical perineal and radical retropubic prostatectomy. Urology 2010;76:417-22.

6. Garg T, See WA. Bladder neck contracture after radical retropubic prostatectomy using an intussuscepted vesico- urethral anastomosis: incidence with long-term follow-up. BJU Int 2009;104:925-8.

7. Jacobsen A, Berg KD, Iversen P, et al. Anastomotic complications after robot-assisted laparoscopic and open radical prostatectomy. Scand J Urol 2016;50:274-9.

8. Sullivan L, Williams SG, Tai KH, et al. Urethral stricture following high dose rate brachytherapy for prostate cancer. Radiother Oncol 2009;91:232-6.

9. Singhal S, Jamaluddin MF, Lee E, et al. Clinical factors and dosimetry associated with the development of prostate brachytherapy-related urethral strictures: A matched casecontrol study. Brachytherapy 2017;16:797-805.

10. Kranz J, Maurer G, Maurer U, et al. Urethral stricture rate after prostate cancer radiotherapy: Five-year data of a certified prostate cancer center. Urologe A 2017;56:336-41.

11. Mohammed N, Kestin L, Ghilezan M, et al. Comparison of acute and late toxicities for three modern high-dose radiation treatment techniques for localized prostate cancer. Int J Radiat Oncol Biol Phys 2012;82:204-12.

12. Uchida T, Ohkusa H, Nagata $Y$, et al. Treatment of localized prostate cancer using high-intensity focused ultrasound. BJU Int 2006;97:56-61.

13. Ahmed HU, Zacharakis E, Dudderidge T, et al. Highintensity-focused ultrasound in the treatment of primary prostate cancer: the first UK series. Br J Cancer 2009;101:19-26.

14. Rodriguez SA, Arias Funez F, Bueno Bravo C, et al. Cryotherapy for primary treatment of prostate cancer: intermediate term results of a prospective study from a single institution. Prostate Cancer 2014;2014:571576.

15. Aus G, Pileblad E, Hugosson J. Cryosurgical ablation of the prostate: 5 -year follow-up of a prospective study. Eur Urol 2002;42:133-8.

16. Park R, Martin S, Goldberg JD, et al. Anastomotic strictures following radical prostatectomy: insights into incidence, effectiveness of intervention, effect on continence, and factors predisposing to occurrence. Urology 2001;57:742-6.

17. Zelefsky MJ, Wallner KE, Ling CC, et al. Comparison of the 5 -year outcome and morbidity of three-dimensional conformal radiotherapy versus transperineal permanent iodine-125 implantation for early-stage prostatic cancer. J Clin Oncol 1999;17:517-22.

18. Ramirez D, Zhao LC, Bagrodia A, et al. Deep lateral transurethral incisions for recurrent bladder neck contracture: promising 5 -year experience using a standardized approach. Urology 2013;82:1430-5.

19. Vanni AJ, Zinman LN, Buckley JC. Radial urethrotomy 
and intralesional mitomycin $\mathrm{C}$ for the management of recurrent bladder neck contractures. J Urol 2011;186:156-60.

20. Eltahawy E, Gur U, Virasoro R, et al. Management of recurrent anastomotic stenosis following radical prostatectomy using holmium laser and steroid injection. BJU Int 2008;102:796-8.

21. Reiss CP, Pfalzgraf D, Kluth LA, et al. Transperineal reanastomosis for the treatment for highly recurrent anastomotic strictures as a last option before urinary diversion. World J Urol 2014;32:1185-90.

22. Ivaz S, Bugeja S, Frost S, et al. Open repair of bladder neck contracture (BNC) with or without adjuvant radiotherapy - our experience in 42 patients. J Urol 2017;197:e574-5.

23. Rourke K, Kinnaird A, Zorn J. Observations and outcomes of urethroplasty for bulbomembranous stenosis after radiation therapy for prostate cancer. World J Urol 2016;34:377-82.

24. Hofer MD, Zhao LC, Morey AF, et al. Outcomes after urethroplasty for radiotherapy induced bulbomembranous urethral stricture disease. J Urol 2014;191:1307-12.

25. Pfalzgraf D, Beuke $M$, Isbarn $H$, et al. Open retropubic reanastomosis for highly recurrent and complex bladder neck stenosis. J Urol 2011;186:1944-7.

26. Nikolavsky D, Blakely SA, Hadley DA, et al. Open reconstruction of recurrent vesicourethral anastomotic stricture after radical prostatectomy. Int Urol Nephrol 2014;46:2147-52.

27. Musch M, Hohenhorst JL, Vogel A, et al. Robot-assisted laparoscopic $\mathrm{Y}-\mathrm{V}$ plasty in 12 patients with refractory bladder neck contracture. J Robot Surg 2018;12:139-45.

28. Cormio L, Massenio P, Lucarelli G, et al. Hem-o-lok clip: a neglected cause of severe bladder neck contracture and consequent urinary incontinence after robotassisted laparoscopic radical prostatectomy. BMC Urol 2014;14:21.

29. Madden-Fuentes RJ, Peterson AC. Pubic Bone Osteomyelitis and Pubosymphyseal Urinary Fistula: A Poorly Recognized Complication in Prostate Cancer Survivors. Oncology (Williston Park) 2017;31:169-73.

30. Veeratterapillay R, Pickard RS. Long-term effect of urethral dilatation and internal urethrotomy for urethral strictures. Curr Opin Urol 2012;22:467-73.

31. Merrick GS, Butler WM, Tollenaar BG, et al. The dosimetry of prostate brachytherapy-induced urethral strictures. Int J Radiat Oncol Biol Phys 2002;52:461-8.

32. Merrick GS, Butler WM, Wallner KE, et al. Risk factors for the development of prostate brachytherapy related urethral strictures. J Urol 2006;175:1376-80; discussion 1381.

33. Matsushita K, Ginsburg L, Mian BM, et al. Pubovesical fistula: a rare complication after treatment of prostate cancer. Urology 2012;80:446-51.

34. Hanna JM, Peterson AC, Mantyh C. Rectourethral fistulas in the cancer survivor. Curr Opin Urol 2014;24:382-8.

35. Hanna JM, Turley R, Castleberry A, et al. Surgical management of complex rectourethral fistulas in irradiated and nonirradiated patients. Dis Colon Rectum 2014;57:1105-12.

36. Redshaw JD, Broghammer JA, Smith TG 3rd, et al. Intralesional injection of mitomycin $\mathrm{C}$ at transurethral incision of bladder neck contracture may offer limited benefit: TURNS Study Group. J Urol 2015;193:587-92.

37. Sourial MW, Richard PO, Bettez M, et al. Mitomycin-C and urethral dilatation: A safe, effective, and minimally invasive procedure for recurrent vesicourethral anastomotic stenoses. Urol Oncol 2017;35:672.e15-9.

38. Milroy EJ, Chapple CR, Cooper JE, et al. A new treatment for urethral strictures. Lancet 1988;1:1424-7.

39. McNamara ER, Webster GD, Peterson AC. The UroLume stent revisited: the Duke experience. Urology 2013;82:933-6.

40. Kuyumcuoglu U, Eryildirim B, Tarhan F, et al. Antegrade endourethroplasty with free skin graft for recurrent vesicourethral anastomotic strictures after radical prostatectomy. J Endourol 2010;24:63-7.

41. Mundy AR, Andrich DE. Posterior urethral complications of the treatment of prostate cancer. BJU Int 2012;110:304-25.

42. Simonato A, Gregori A, Lissiani A, et al. Two-stage transperineal management of posterior urethral strictures or bladder neck contractures associated with urinary incontinence after prostate surgery and endoscopic treatment failures. Eur Urol 2007;52:1499-504.

43. Theodoros C, Katsifotis C, Stournaras P, et al. Abdominoperineal repair of recurrent and complex bladder neckprostatic urethra contractures. Eur Urol 2000;38:734-40; discusssion 740-1.

44. Wessells H, Morey AF, McAninch JW. Obliterative vesicourethral strictures following radical prostatectomy for prostate cancer: reconstructive armamentarium. J Urol 1998;160:1373-5.

45. Fuchs JS, Hofer MD, Sheth KR, et al. Improving Outcomes of Bulbomembranous Urethroplasty for Radiation-induced Urethral Strictures in Post-Urolume Era. Urology 2017;99:240-5.

46. Ahyai SA, Schmid M, Kuhl M, et al. Outcomes of Ventral 
Onlay Buccal Mucosa Graft Urethroplasty in Patients after Radiotherapy. J Urol 2015;194:441-6.

47. Reiss CP, Rosenbaum CM, Becker A, et al. The T-plasty: a modified $\mathrm{YV}$-plasty for highly recurrent bladder neck contracture after transurethral surgery for benign hyperplasia of the prostate: clinical outcome and patient satisfaction. World J Urol 2016;34:1437-42.

48. Rey D, Helou E, Oderda M, et al. Laparoscopic and robotassisted continent urinary diversions (Mitrofanoff and YangMonti conduits) in a consecutive series of 15 adult patients: the Saint Augustin technique. BJU Int 2013;112:953-8.

49. Flum AS, Zhao LC, Kielb SJ, et al. Completely intracorporeal robotic-assisted laparoscopic augmentation enterocystoplasty with continent catheterizable channel. Urology 2014;84:1314-8.

50. Pagliara TJ, Liberman D, Elliott S. Minimally invasive continent catheterizable ileal cecocystoplasty 2015. Available online: https://www.youtube.com/watch?v=8GM vuasLECI\&feature=youtu.be

51. Wagner J, Haddock P. Robotic-assisted laparoscopic catheterizable bladder augment: a novel approach to treat recurrent bladder neck contracture following radical prostatectomy. Can J Urol 2015;22:8074-8.

52. Gousse AE, Tunuguntla HS, Leboeuf L. Two-stage management of severe postprostatectomy bladder neck contracture associated with stress incontinence. Urology 2005;65:316-9.

53. Cox A, Herschorn S. Management of the incontinent patient with a sphincteric stricture following radical prostatectomy. Curr Opin Urol 2014;24:578-85.

54. Ajay D, Potts B, Feltner C, et al. Outcomes of Transobturator Sling Placement in Men with Incontinence Secondary to Radical Prostatectomy and Radiotherapy for Prostate Cancer: A Systematic Review. J Urol 2016;195:e1185.

Cite this article as: Kahokehr AA, Peterson AC, Lentz AC. Posterior urethral stenosis after prostate cancer treatment: contemporary options for definitive management. Transl Androl Urol 2018;7(4):580-592. doi: 10.21037/tau.2018.04.04
55. Anger JT, Raj GV, Delvecchio FC, et al. Anastomotic contracture and incontinence after radical prostatectomy: a graded approach to management. J Urol 2005;173:1143-6.

56. Kranz J, Anheuser P, Rausch S, et al. Continent ileovesicostomy after bladder neck closure as salvage procedure for intractable incontinence. Cent European J Urol 2014;66:481-6.

57. VanDyke ME, Viers BR, Pagliara TJ, et al. Permanent bulbar urethral ligation: emerging treatment option for incontinent men with end-stage urethra. Urology 2017;105:186-91.

58. Anderson KM, Higuchi TT, Flynn BJ. Management of the devastated posterior urethra and bladder neck: refractory incontinence and stenosis. Transl Androl Urol 2015;4:60-5.

59. Ullrich NF, Wessells H. A technique of bladder neck closure combining prostatectomy and intestinal interposition for unsalvageable urethral disease. J Urol 2002;167:634-6.

60. Patil MB, Hannoun D, Reyblat P, et al. Total bladder and posterior urethral reconstruction: salvage technique for defunctionalized bladder with recalcitrant posterior urethral stenosis. J Urol 2015;193:1649-54.

61. Faris SF, Milam DF, Dmochowski RR, et al. Urinary diversions after radiation for prostate cancer: indications and treatment. Urology 2014;84:702-6.

62. Worst TS, Daskalova K, Steidler A, et al. Novel insights into a reputably irreversible process: combined mRNA and miRNA profiling of tissue from vesicourethral anastomotic stenosis after radical prostatectomy. World J Urol 2017;35:1701-11.

63. Shah N, Laungani R, Sand M. Endoscopcic injection of placental based cryopreserved amniotic allograft for treatment of recurrent bladder neck contracture. South Eastern Section of AUA- Annual Scientific Meeting abstract book; Austin, Texas: 2017;260. 